\title{
Economías afectivas y verdades parciales en el contexto de las exhumaciones en Navarra
}

\author{
Ekonomia afektiboak eta egiia partzialak Nafarroako exhumazioen \\ testuinguruan
}

Affective economies and partial truths in the context of exhumations in Navarre

\author{
Dorothée Delacroix \\ Université Sorbonne Nouvelle \\ dorothee.delacroix@sorbonne-nouvelle.fr \\ https://orcid.org/0000-0003-1377-0648
}

\begin{abstract}
Resumen
La nueva centralidad que adquieren los restos humanos, al ser expuestos a la luz pública tras su exhumación, es ambivalente. Cuerpo prueba, cuerpo artefacto, cuerpo adoptado bajo una identidad ficticia, cuerpo medio y límite de imputación de responsabilidades: la etnografía presentada en este artículo se basa en Navarra e ilustra los diferentes sentidos atribuidos a los restos exhumados. Se muestra cómo experiencias concretas de "verdad" se ponen a prueba de forma muy variada entre y dentro de los contextos. Estas experiencias se apoyan en las diferentes huellas que articulan registros contradictorios y complementarios. Los saberes son forenses, archivísticos, locales. Las movilizaciones pueden ser colectivas o privilegiar el luto individual, y los registros afectivos y políticos se entremezclan. El análisis demuestra que diferentes formas de apaciguamiento están en tensión entre dos polaridades: por una parte, la discursividad y por otra la materialidad de los restos.
\end{abstract}

Palabras clave

Exhumaciones; franquismo; verdad; restos humanos; ADN; emociones; pericia forense.

\section{Sumario}

1. LOS REStOS EXHUMAdOS: UNA MEDIA VeRDAD ESPECTACULARIZADA. 2. Del "MEDIO LUTO» a LAS AdOPCIONES SIMBÓLICAS. 3. CONCLUSIÓN. BIBLIOGRAFÍA. 
Laburpena. Giza gorpuzkiek lurpetik atera eta argitara ekartzen direnean hartzen duten zentralitatea anbibalentea da. Gorputza froga, gorputza artefaktu, gorputza fikziozko nortasun baten azpian hartua, gorputza erantzukizunak egozteko bitarteko eta muga: artikulu honetan aurkezten den etnografia Nafarroan dago oinarritua, eta lurpetik ateratako gorpuzkiei nolako esanahia eman zaien erakusten du. Artikuluan, agerian jartzen da "egiaren» esperientzia zehatz batzuei nola egiten zaien proba oso modu diferenteetan testuinguruen artean eta barrenean. Izan ere, esperientzia horien oinarrian dauden aztarnek erregistro kontraesankorrak eta osagarriak antolatzen dituzte. Jakintza auzitegietakoa, artxiboetakoa, lokala da; mobilizazioak, berriz, kolektiboak izan litezke edo banakako doluari ematen ahal diete lehentasuna, eta erregistro afektiboak eta politikoak nahasi egiten dira. Artikulu honetako analisiak frogatzen du bakeak egiteko moduak tentsioan daudela honako bi mutur hauen artean: diskurtsibotasuna, batetik, eta gorpuzkien materialtasuna, bestetik.

Gako hitzak. Exhumazioak; frankismoa; egia; giza gorpuzkiak; DNA; emozioak; adituen azterketa forentsea.

\begin{abstract}
The new centrality that human remains acquire when they are exposed to the public eye after their exhumation is ambivalent. The ethnography presented in this article is about Navarra and illustrates the different meanings attributed to exhumed remains. It focuses on the body as proof, as an artifact, on the body adopted under a fictitious identity, or seen as medium or as a limit to the settling of responsibilities. It shows how concrete experiences of "truth" are used as a regime of proof in a wide variety of ways between and within contexts. These experiences are supported by the different marks that articulate contradictory and complementary registers. Sources of knowledge are forensic, archival, local. Mobilizations can be collective or privilege individual mourning, and affective and political registers are intermingled. The analysis shows that different forms of appeasement are in tension between two polarities: on the one hand, discursivity and, on the other, the materiality of the remains.
\end{abstract}

Keywords. Exhumations; Francoism; truth; human remains; DNA; emotions; forensic expertise.

Desde hace una veintena de años, las exhumaciones relacionadas con los conflictos armados del siglo Xx han aumentado considerablemente en todo el mundo, hasta tal punto que esta realidad es calificada de forensic turn. Este auge está vinculado a la profesionalización de las exhumaciones, asociada a los progresos recientes de la medicina legal, sobre todo en términos de identificación de los cuer$\operatorname{pos}^{1}$. De igual forma, un marco jurídico a escala global ha favorecido el desarrollo masivo de las exhumaciones ${ }^{2}$; de esta manera, tanto en los tribunales penales nacionales como en los internacionales, los jueces abogan cada vez más por la utilización de peritajes médicos. Debido a estos factores combinados, miles de restos humanos son desenterrados y analizados en los laboratorios para ser identificados. Esta práctica extensiva y mundial de exhumaciones de cadáveres procedentes de

1 Anstett y Dreyfus, 2015.

2 Dziuban, 2017. «Es importante considerar que las exhumaciones en España están directamente relacionadas con excavaciones similares en otras partes del mundo, en el marco de los discursos y las prácticas sobre la defensa de los derechos humanos a escala ǵlobal (Ferrándiz y Robben 2015)». Ferrándiz, 2018, p. 293. 
la violencia masiva ha llevado a Ferrándiz ${ }^{3}$ a calificar nuestra época como la «era del hueso». En España, entre el año 2000 y el 2018, se realizaron más de 740 exhumaciones relacionadas con la guerra civil española y con la dictadura del general Franco y se han recuperado de esta forma los restos de más de 9000 individuos ${ }^{4}$.

El vacío creado por la ausencia de los desaparecidos durante la violencia masiva sería ocupado hoy en día por otra faceta valorada de la identidad, la inscrita en la sangre y los genes ${ }^{5}$. Este artículo pretende examinar esta afirmación tomando como objeto de estudio la apertura de las fosas comunes del franquismo en Navarra, donde más de 3000 personas fueron asesinadas a consecuencia de la violencia desatada en la retaguardia ${ }^{6}$. Diversos dispositivos administrativos, políticos y simbólicos acompañan la recuperación de restos humanos. Estos plasman distintas representaciones del pasado de violencia, del cuerpo maltratado y de la relación que la víctima establece consigo misma no solo en tanto que tal sino también en tanto que ciudadano cuyo el derecho de vivir de sus antepasados fue negado. Los restos humanos recuperados tras las exhumaciones son a la vez objetos de reivindicaciones políticas, pilares de una economía afectiva y elementos claves de un sistema de pruebas basado en el saber científico ${ }^{7}$. Se analiza aquí los sentidos y las emociones múltiples que se proyectan en ellos, haciendo de las experiencias de su «retorno» algo muy complejo de procesar, incluso por los propios familiares. Para dar cuenta de ello, se analiza la manera en la que los «regímenes de verdad» ${ }^{8}$ concurren, cohabitan y dan un sentido a esta nueva configuración bio-científica, arraigada en un resurǵimiento masivo de los represaliados. En primer lugar, se cuestiona la índole de la «verdad» que ofrece la recuperación de los restos humanos. En segundo lugar, se analiza el lugar que ocupan los restos exhumados en la economía afectiva de los nietos de las víctimas del franquismo.

Varios estudios han analizado la tensión existente entre los registros genealógicos y políticos ${ }^{9}$, a veces también paródicos ${ }^{10}$, a los que recurren los actores y los

3 Ferrándiz, 2014.

4 Etxeberria y Solé, 2019, pp. 404-405.

5 Gatti, 2014a; Gatti y Anstett, 2018; Gatti y Mahlke, 2018; Capdepón, 2018.

6 Altafaylla, 2018.

7 Aunque estos peritajes forenses actualmente no son considerados por la esfera jurídica, son sin embargo archivados con el objetivo de establecer en el futuro un corpus de características de las escenas del crimen y documentar el proceso de las acciones que han producido los asesinatos.

8 Foucault, 2012. Para Foucault, la noción de «regímenes de verdad» se refiere a los tipos de relación que vinculan las manifestaciones de la verdad con sus procedimientos y los sujetos que son sus operadores, testigos o eventualmente objetos. La noción permite así articular las cuestiones del saber y del poder (vinculadas a la producción de la verdad por parte de los dominantes) con las tecnologías del ser, es decir aquellas formas en que se elaboran las verdades «internas», como actitudes críticas de transformación y emancipación de las formas de sujeción.

9 Gatti, 2014a; Capdepón, 2018.

10 Sosa, 2014. 
militantes para abordar el pasado de violencia y para movilizarse en un contexto en el que el ADN ha ocupado un lugar central en la búsqueda de desaparecidos y de bebés robados. Dichos trabajos se enfocan principalmente en el caso argentino y, más precisamente, en el papel relevante que tuvieron allí las Abuelas de la plaza de Mayo $^{11}$. En la medida en que circulan entre Arǵentina y España experiencias militantes, símbolos (como el pañuelo), vocabulario (como el término «detenido-desaparecido»), prácticas forenses y, más recientemente, una relación jurídica (mediante la Querella arǵentina), el análisis comparativo es de suma relevancia ${ }^{12}$. Además, diferentes estudios constatan en ambos casos una valoración de la identidad genética. Esta nueva configuración conllevaría una privatización de la memoria, una descontextualización de los hechos y de los protagonistas, y participaría, in fine, en su despolitización y en la construcción de una imagen de víctima inocente. A la luz de estos análisis recientes y sobre la base de mis materiales etnográficos, acuerdo con el hecho de que el hallazgo de restos humanos se inscribe, sin duda alguna, en un régimen materialista basado en saberes forenses que se ha vuelto un elemento clave del activismo memorialista, sin embarǵo este régimen de verdad no es el único, ya que existe de manera simultánea con otros, centrados en los archivos históricos y en las construcciones simbólicas que implican el recurso a formas aumentadas de la corporeidad y a un parentesco electivo. Analizo además la relación ambigua de las familias con las exhumaciones que a su vez reivindican y se apropian políticamente pero cuyos resultados quedan insuficientes para llenar muchos interrogantes, dejando así espacio a verdades parciales, heterogéneas e íntimas.

En otras palabras, si el esfuerzo de esclarecimiento de «la» verdad mediante la exhumación y la identificación del $\mathrm{ADN}$ de restos humanos objetiva, con una mirada naturalista, el cuerpo del delito - a veces no sin violencia simbólica- y contribuye a inscribirlo en una genealogía, la situación no se caracteriza exclusivamente por una rigidez de la identidad de los muertos y de la relación con el pasado. Para poder entender la complejidad de los discursos sobre los restos humanos exhumados y los gestos y conmemoraciones que los rodean, me apoyaré en las subjetividades de los actores que gravitan a pie de fosa y hacen coexistir diferentes modos de verdad basados en una inteligibilidad diferente de las huellas del pasado ${ }^{13}$.

${ }^{11}$ La última dictadura militar argentina (1976-1983) puso en práctica un plan sistemático de robo de bebés de opositores políticos. La organización «Abuelas de la Plaza de Mayo» estima en 500 el número de bebés robados. A finales de 2017, 127 identidades habían podido ser restituidas. Para un análisis crítico del «poder de la sanǵre» en este contexto, véase Gatti, 2014a.

12 Véase Gatti, 2014b; Montoto Ugarte, 2021.

${ }^{13}$ Dos exhumaciones realizadas en Navarra han sido objeto de observaciones participantes. Durante las fases de las excavaciones, que se desarrollaban durante el fin de semana, llevé a cabo un trabajo de investigación que involucraba a los profesionales de las exhumaciones, a las familias, a 


\section{Los restos exhumados: una media verdad espectacularizada}

Paraje de «las Tres Cruces», municipio de Ibero (a $20 \mathrm{~km}$ de Pamplona), 6 de diciembre de 2015. Efervescencia a pie de fosa. Los restos humanos de cinco personas fueron descubiertos la víspera. La noticia ha sido difundida por los periódicos locales. El equipo técnico de Aranzadi -al que ayudo como parte del trabajo de observación participante- se esmera en limpiar al máximo los esqueletos in situ «para que queden bonitos», es decir, presentables públicamente. Hecho esto, llega el momento de las fotos con los políticos, antes de meter cuidadosamente los restos en cajas de plástico numeradas y luego analizarlos en el laboratorio de San Sebastián. Entre las numerosas fotografías tomadas en el lugar, algunas tienen un objetivo científico. Estas documentan la posición de los restos humanos y su orientación. Para ello, la escala métrica, los puntos cardinales y los pequeños caballetes con los números que sirven para singularizar a los restos deben estar bien visibles en el momento de la toma. Otras fotografías son ilustrativas. Son realizadas por periodistas y por miembros de las asociaciones memorialistas y de familiares de víctimas del franquismo. Se pueden encontrar enseguida en los blogs y periódicos, pero principalmente alimentan los enormes archivos de fotos compartidas en Internet dentro de una gran red interpersonal. Los esqueletos, a menudo solamente fraǵmentos de esqueletos, también son fotografiados con teléfonos móviles, algúnos hacen selfis y los comparten instantáneamente ${ }^{14}$. Al lado de los restos, también posan representantes políticos, miembros del equipo técnico y familiares de los ejecutados. Estos últimos critican a veces a los primeros: «Llegan demasiado tarde». Otras acusaciones sordas surgen contra los vecinos de los lugares de entierros que han venido para ver o ayudar, pero cuyos familiares mayores (incluso ya fallecidos) son acusados de haber colaborado con el bando

los vecinos de los lugares de los enterramientos, a los miembros de las asociaciones de fusilados y a las instituciones (representantes de los ayuntamientos y del Gobierno de Navarra). Las relaciones establecidas en el momento de las exhumaciones fueron el punto de partida de un estudio más profundo de estos actores durante un período de cuatro años en el que pude llevar a cabo siete meses de trabajo de campo. Además de las conversaciones informales, más de 80 entrevistas fueron realizadas a unas cuarenta personas, cinco de ellas eran miembros o ex miembros del equipo técnico de Aranzadi. La realización de este trabajo, desarrollado desde 2015, fue posible gracias al apoyo inicial del LESC y a la financiación de mis investigaciones posdoctorales por la Casa de Velázquez (2016-2017) y luego por una beca Cofund Marie Sk. Curie (2017-2019). Este artículo es una versión revisada, aumentada y centrada en el caso español de Delacroix y Noûs, 2020. Para su traducción se ha contado con el apoyo del proyecto de investigación Transfunerario, financiado por la ANR. Quisiera aǵradecer a Manuel Balbuena por su trabajo de traducción así como a Stéphane Michonneau y Zoé de Kerangat por sus comentarios. Uso seudónimos para nombrar a mis interlocutores.

14 Ferrándiz, 2018. 
nacional-católico. En resumen, estos restos humanos que habían sido mantenidos en el anonimato durante ocho décadas son propulsados y sobreexpuestos, un poco de forma paracrónica, en un mundo en el que les espera una comunidad familiar y política ampliada ${ }^{15}$, pero muy dividida. Su singular existencia social, en este inicio del siǵlo XXI, plantea la cuestión de la temporalidad de su vida social y de los modos rituales y políticos en función de los cuales se recomponen su estatus y su lugar en la sociedad actual ${ }^{16}$.

Entre 2015 y 2019 en Navarra, al iǵual que en otras comunidades autónomas (sobre todo Andalucía, Cataluña y el País Vasco), las formaciones políticas en el poder han promovido diversas acciones a favor de la memoria histórica ${ }^{17}$. Estas constituyeron un cambio importante con los antiguos gobiernos que consideraban no prioritario o incluso innecesario y divisivo el hecho de proceder a estas exhumaciones. Este reconocimiento oficial marcó un punto de inflexión fundamental de las políticas publicas respecto a la memoria del golpe de estado de 1936 y de sus consecuencias. Las exhumaciones de las fosas comunes del franquismo se volvieron así un elemento clave tanto del activismo memorialista (que autofinanciaba antes las excavaciones) como de la acción publica (que asumió entonces la financiación de la búsqueda de los restos $)^{18}$.

Este compromiso político recibió una gran cobertura mediática. Sin embargó, para algunas familias de víctimas con las que se realizó la investigación etnográfica, se desarrolló asimismo un patetismo televisado y un uso indecente y abusivo del duelo y de las emociones. En efecto, aunque los allegados de las personas asesinadas se hayan vuelto más visibles y se sientan más escuchados en esta configuración política, no es menos cierto que también alguunos de ellos se encuentran incómodos por haber sido colocados bajo los focos de los proyectores por intereses que les parecen fuera del contexto, que sean políticos, electorales o mediáticos. Por lo tanto, tienen la sensación de ser en parte instrumentalizados. Entre los más críticos, algunos nietos de personas ejecutadas durante la guerra civil llegan incluso a lamentar encontrarse en el centro de lo que ellos consideran como una pornografía de la violencia y una exposición violenta del testigo por parte de personas que «hicieron imaǵen con la memoria»: «¿Cuántas veces vamos a tener

${ }^{15}$ Capdepón, 2018; Ferrándiz, 2014.

${ }^{16}$ Un trabajo pionero sobre estos temas es el de Verdery 1999.

${ }^{17}$ En el momento de la investiǵación, entre 2015 y 2019, las principales instituciones de la Comunidad Foral de Navarra contaban con el apoyo de cuatro formaciones políticas de ámbito nacionalista/vasquista y de izquierdas: Geroa Bai, EH Bildu, Podemos e Izquierda-Ezkerra. Mientras el gobierno estaba liderado por Geroa Bai, coalición de varios grupos independientes y el PNV, la izquierda abertzale (EH-Bildu) era quien ocupaba la alcaldía del ayuntamiento de Pamplona.

${ }^{18}$ Hay que mencionar, entre otros aspectos, el carácter pionero de la Ley Foral 33/2013 en la financiación de las exhumaciones. Véase en particular Garmendia Amutxastegii y García Funes, 2015. 
que desnudarnos delante de las cámaras, los micros y los políticos? ¿Cuántas veces vamos a tener una y otra vez que contar nuestras experiencias?» ${ }^{19}$.

Expresan su resistencia a una visibilidad pública otorgada en la que no se reconocen y que consideran victimizante cuando cae en la obscenidad de los detalles sórdidos o el melodrama ${ }^{20}$. Definitivamente, esta incomodidad con respecto a la visibilidad pública de los familiares, al tratamiento sentimental de su dolor y a la espectacularización macabra de las exhumaciones está conectada con «debates semejantes en el periodismo, la ayuda humanitaria y, naturalmente, en las Humanidades y las Ciencias sociales, sobre cuestiones como límites que deben establecerse al representar el horror, la manipulación comercial del dolor y la barbarie, la pornografía de la violencia, los efectos de un exceso de representación o los ciclos de saturación de empatía en la sociedad del espectáculo» ${ }^{21}$.

El exceso de sentimentalismo es importante de mencionar. Por lo tanto, no debe ocultar el abanico de emociones y posiciones que los familiares movilizan y ocupan, contribuyendo activamente a la afirmación de su propia dignidad y a una distancia crítica con una manipulación del dolor interesada. También, habría que matizar el aspecto generacional de la experiencia que se tiene de la mediatización y del uso político de las memorias de la guerra civil. Para los hijos de personas asesinadas por el bando nacional-católico son importantes las formas de reconocimiento y homenajes públicos de la memoria de sus padres. Estas también lo son para la generación de los nietos, pero entre estos últimos es posible que las críticas puedan ser más intensas:

Los ancianos dicen: «ioh, qué suerte, el alcalde va a venir!» porque [nuestros padres] son [sic] educados así, pero a nosotros [los nietos] no nos interesa tanto. Los medias [sic] cubren a las autoridades. Estas hacen una placa que les conviene pero que no dice toda la verdad. [...] Para ser completo el homenaje

19 Miren, Pamplona, 13 de marzo del 2017. Conocí a Miren en la exhumación de Ibero en diciembre de 2015. Desde entonces nos hemos visto una decena de veces en diferentes contextos: en la búsqueda de fosas, en el Archivo Real y General de Navarra, en su domicilio, en actividades orǵanizadas por las asociaciones de familias de fusilados o, incluso, en comidas o veladas tanto en su entorno familiar como también fuera de él.

${ }^{20}$ La teoría queer y la de la performance utilizada por Sosa (2014) para analizar el caso argentino superan eficazmente elacercamiento basado en el traumatismo y el luto melancólico. Más allá de la crítica de la biologización de la memoria, Sosa muestra la gran diversidad de registros paródicos y de humor neǵro a los que ciertos hijos de desaparecidos recurren a través de sus producciones culturales no victimizantes y liberadas de una focalización en los lazos de sanǵre. Estas elecciones inventivas en la manera de abordar la memoria y de entender el luto fuera del arquetipo de la «familia herida» han sido asimismo realizadas por cineastas y artistas que no tienen filiación con los desaparecidos y que contribuyen, ellos también, a dibujar los contornos de una «aleǵre comunidad en duelo».

${ }^{21}$ Ferrándiz, 2018, p. 302. 
tiene que llevarme algo más, pero no se puede decir nada que pueda molestar al pueblo [donde se encuentra la fosa]. La verdad es que acá, el perdón público no se ha dado.

El fondo de su enfado es a menudo similar: la ausencia de perdón público, el silencio que rodea a los perpetradores de violencia ${ }^{22}$ y la producción, a fin de cuentas, de una memoria consensual. En consecuencia, si bien estos restos humanos que resurgen son un testimonio de la represión masiva ejercida contra algunos individuos acusados de defender la República en una reǵión de España donde no hubo un frente militar, siguen sin poder expresar «toda la verdad», en particular la relacionada con las acciones individuales y colectivas que condujeron a las ejecuciones. Adaptado a la situación española y para caracterizar la amplitud del fenómeno, el concepto de «zona gris» de Primo Levi se convierte en palabras de mi interlocutora en una «masa gris». Ella explica:

Ya sabemos muy bien lo que eran y quiénes eran las víctimas. ¿Cuándo van a enfocar la mirada a los culpables y esa masa gris? Aquí no vinieron de fuera a asesinarlos, sino que fueron nuestros propios vecinos e incluso a veces parientes los que llevaron a cabo las delaciones, los saqueos, las detenciones y los asesinatos. Esos pueblos donde se han encontrado las fosas comunes eran conocedores TODOS de qué era eso. Esos pueblos con sus autoridades hicieron el trabajo final, tapar los cadáveres, robarles, desdibujar la zona, verter encima de ellos basura o decidir que por ahí iba a pasar la carretera. ¡Esa complicidad no mencionada la echo de menos! [...] Hace apenas un mes y medio, en una exhumación, un chico maravilloso y muy empático me preguntó: ¿Y tu abuelo qué hizo? ¿Cómo puede ser que en pleno siǵlo XXI un muchacho de 30 años crea que tuvo que haber hecho algo esa víctima para merecerse lo que le dieron y sigue aun hoy desaparecido? ${ }^{23}$.

Las expectativas de las familias en cuanto al esclarecimiento de las zonas oscuras del pasado son a veces superiores a las respuestas que pueden ofrecer los protocolos de objetivación del crimen permitidos por el peritaje forense. Los resultados de los análisis de $\mathrm{ADN}$ solo proporcionan una parte de la información anhelada ya que, a pesar de restituir a veces la identidad de una persona, no restablecen ni toda su historia, ni la red de responsabilidades que llevaron a su ase-

22 «Perpetradores» designa a los autores de violencia en un sentido más amplio que el de «asesinos». Se refiere no solamente a los que hayan matado, sino también a las personas que hayan participado en la delación o cualquier otra práctica que haya provocado indirectamente la muerte, la tortura o la detención arbitraria. Para un análisis histórico de estos actores en Navarra, ver Mikelarena, 2015.

2319 de octubre de 2017. 
sinato. Por esta razón, algunos descendientes de familias represaliadas durante el golpe de Estado y la dictadura franquista emprenden un verdadero trabajo de historiador amateur. Entre los esfuerzos colectivos y extraoficiales «para-forenses» la «exhumación archivística» ${ }^{24}$ constituye una de sus contribuciones significativas. De hecho, Miren fue ella quien me guió en las investigaciones que realicé en algunas ocasiones en el Archivo General de Navarra. Comprender el contexto histórico y el perfil sociológico y biográfico de los asesinos de sus antepasados es, por lo tanto, uno de los objetivos buscados por algunas familias para las que el cuerpo recuperado solo constituye una «media verdad»:

Alrededor de una tumba, durante una excavación o una exhumación, se escuchan tantas justificaciones de los habitantes del pueblo donde se encuentran estas fosas que se vuelve hiriente. La realidad es que, de una forma $\mathrm{u}$ otra, un miembro de su familia siempre está involucrado por acción u omisión. El cuerpo que me devuelven no me trae más que medio luto, media verdad y, al final, una paz imperfecta.

En contra de la idea según la cual los restos humanos analizados en laboratorio constituyen una materialidad «pura», directa, portadora de alivio y de significado en sí misma, fuera de todo contexto, Miren señala las prácticas doblemente limitadas en la manera en que los restos son exhumados y homenajeados. La recuperación de los restos, al iǵual que la monumentalidad pública y los homenajes posteriores, no necesariamente logran colmar las expectativas sociales de las familias que reivindican identidades más complejas que aquellas centradas en los restos humanos y en los resultados de los análisis de $\mathrm{ADN}$ que, a veces, las relacionan a estos restos recobrados. Desde el punto de vista de algunas de ellas, el lenguaje conmemorativo y político formulado a cerca de la memoria de la Guerra Civil y del franquismo elude las zonas ǵrises y propone una recuperación de los restos en parte descontextualizada, reavivando aún más la sensación de impunidad de los culpables del crimen. La voluntad por conocer y por dar a conocer la mecánica de la perpetración de las ejecuciones extrajudiciales marca una distancia crítica con la sobrevaloración de los restos, véase incluso su fetichización, en un régimen presentista $^{25}$ construido en torno a una búsqueda ardiente de los cuerpos ${ }^{26}$.

${ }^{24}$ Douǵlas, 2021.

${ }^{25}$ Hartog, 2003.

${ }^{26}$ La defensa de una visión arqueológica de la memoria de España (a través de la actualización de los huesos que presentan un relato irrefutable sobre el pasado) responde también a la gran desconfianza que hay con respecto de los historiadores, acusados de colusión con la dictadura franquista primero y con la joven democracia después y sobre los que pesa la sospecha de un acuerdo secreto con las élites del país en favor del olvido. Este contexto implica que el cuerpo exhumado sea esǵrimido como un contra-relato hegemónico y como un medio de resistencia al revisionismo. 
Si bien estas posiciones quizás no son mayoritarias, son interesantes de considerar para destacar tanto las fisuras dentro de los marcos habituales de interpretación de duelos como las disputas que emanan de las expectativas de los giros memorialista y forense. De hecho, ambas proporcionan respuestas y discursos que no siempre son los esperados.

\section{Del «medio luto»a las adopciones simbólicas}

La expresión «fosas comunes» enǵloba lugares muy heterogéneos que no son objeto ni de las mismas políticas de recuperación de los restos a lo largo del tiempo $^{27}$, ni de las mismas prácticas por parte de los familiares de las víctimas, dependiendo de si ellas conocen o no el lugar del enterramiento de su pariente ${ }^{28}$. Si la ausencia del cuerpo plantea la aguda cuestión de los sustitutos del mismo, es decir, de los medios alternativos que las familias y las viudas han puesto en práctica en su proceso de duelo, es posible que su «reaparición» trastorne o modifique dicho proceso. En España, algunas viudas clavaron una herradura en el árbol más cercano al lugar donde habían sido asesinados sus maridos y donde ellas venían a recogerse y a rezar. La localización del árbol les había sido indicada por un sacerdote que tenía información precisa del lugar del entierro ${ }^{29}$. Si bien se mencionó anteriormente el caso arǵentino, otros casos latinoamericanos y asiáticos de gestión del duelo en contextos de posconflicto son muy útiles para entender mejor las similitudes y las diferencias con la situación española. El impacto de la ausencia del cuerpo ${ }^{30}$, las construcciones de formas de duelo y de recuerdo sin cuerpo $^{31}$, las diversas maneras de buscarlo o de comunicar con el desaparecido ${ }^{32}$ y las prácticas funerarias en el contexto de reinhumación son temáticas que se enriquecen al adoptar una perspectiva comparada. En Perú, algunas viudas echan agua bendita y depositan rosas blancas en el lugar donde se supone que fueron enterrados sus maridos, sobre todo cuando este se les aparece en sueños y les cuenta sus sufrimientos ${ }^{33}$. De manera no muy alejada, Fernández de Mata analiza

\footnotetext{
${ }_{27}$ Aguilar Fernández, 2019; Kerangat, 2017.

28 Delacroix, 2017; Robin Azevedo, 2021.

${ }^{29}$ Durante la exhumación de Ibero en diciembre de 2015, fue encontrada una herradura, potencialmente la utilizada por la viuda, en el lugar donde se suponía que había estado la fosa. Los restos, sin embargo, no pudieron ser recuperados. Esta herradura la conserva como una reliquia uno de los nietos, que la hizo enmarcar.

${ }^{30}$ Panizo, 2012.

31 Robledo Silvestre, 2017.

32 Delacroix, 2018; Panizo, 2012; Sorrentino, 2018; Winter, 1995.

33 Delacroix, 2018.
} 
los contra-relatos que circulan en la esfera privada de los vencidos de la guerra civil española y que permiten evocar de forma implícita la crueldad de ciertos protagonistas de la represión franquista y el castigo divino que sufrieron o que les espera ${ }^{34}$.

Además, estas prácticas íntimas de recuerdo, de interpretación de la desǵracia y autoreparación continúan paralelamente a las exhumaciones bajo otras formas y pueden evolucionar. La excavación llevada a cabo en el cementerio abandonado de Lecáun, en Navarra, es un ejemplo de ello. Los días 27 y 28 de junio de 2015, se descubrieron los restos de tres personas en un entierro clandestino en el cementerio de este pueblo. Los posteriores análisis de $\mathrm{ADN}$ desmintieron viejas suposiciones con más de 80 años de antigüuedad: los restos de Eduardo González, el abuelo socialista buscado por alǵunos de sus descendientes, impulsores de la excavación, no aparecieron. Sin embargoo, otros lazos íntimos surgieron fuera de la matriz del ADN. Dos de las nietas de Eduardo, hermanas, relatan este momento:

Paola.- Quien los haya enterrado los enterró muy bien, no uno encima del otro.

Suzana.- Paco [Etxeberria] interrogó a nuestra madre y a nuestras tías. Para ellas era su padre el que estaba allí.

Paola.- Sí, para mí también.

Suzana.- Toda la vida habían oído que podría estar en ese cementerio. Así que dijeron, «Bueno, si no es él, está bien. Son los abuelos de todos». De hecho, va más allá de la familia, ya es social, es colectivo. Vienes a decirte: «Bueno, no es nuestro abuelo», te quedas con la pregunta de en qué se ha convertido, si las pistas que seguimos eran verdaderas o no, pero por otro lado te dices: «iencontramos tres de ellos y eso es un éxito!».

Paola.- Tal vez tengas esta duda, pero estoy muy serena. Yo, mi abuelo, lo he visto. Fue muy simbólico, pero lo vi. Paco Etxeberria lo recogió todo, tomó notas de todo, y yo quería recuperar [los restos de] el que creía que era mi abuelo. Es muy extraño. En realidad, es como si adoptaras uno de los cuerpos. Vi a mi abuelo. Vi su boca, lo vi todo ${ }^{35}$.

Siguiendo a Veena Das ${ }^{36}$, comprobamos que algunas realidades necesitan convertirse en ficción para poder ser percibidas e integradas. Un elemento material, ya sea un cuerpo o a veces solamente un objeto que haya pertenecido al desaparecido o que haya permitido materializar su presencia (como por ejemplo una herradura) plasma una situación dolorosa logrando a la vez distanciarse de ella.

\footnotetext{
${ }^{34}$ Fernández de Mata, 2016.

35 Pamplona, 25 de octubre de 2017.

36 Das, 2016.
} 
Así lo atestigua Paola, que lo vivió como una experiencia terapéutica importante que además completó con la ayuda de un psicólogo intergeneracional navarro, él mismo «nieto de fusilado». En lugar de significar la pérdida de la intimidad de los funerales y el repliegue hacia una «verdadera» identidad, esta situación invita a considerar la recomposición totalmente simbólica de la relación con el desaparecido, posible gracias al trabajo de los expertos forenses y cuyo alcance sobrepasa el marco técnico-científico de la operación. Uno de los esqueletos que fueron descubiertos, con un trabajo paciente, en el cementerio de Lecáun ofreció una materialización corporal de la pérdida sufrida. Y esto, más allá de cuál sea su verdadera identidad.

Como demostró Moisseeff ${ }^{37}$, la presencia de un cuerpo humano conlleva una reacción emocional que, en este caso en concreto, se transforma en una verdad emocional. «Obtener un resultado negativo [del ADN] en el mismo momento [de la exhumación en Lecáun] habría roto toda la magia de esos días de búsqueda», declara Suzana; una excavación vivida muy intensamente por los miembros de la familia que participaron activamente en ella, en la que primos y tías ayudaron en las fases de exhumación y de limpieza de esqueletos y dieron entrevistas a los medios de comunicación a los que habían eleǵido avisar.

«Tenía más miedo de la frustración de los demás que de la mía», continúa Suzana. De hecho, los efectos de las exhumaciones fallidas o inacabadas son importantes de considerar, tanto sobre los familiares como sobre los profesionales ${ }^{38}$. Acerca de estos últimos, estudios recientes han analizado tanto la gestión de sus dudas y frustraciones, como su posición intermedia debida a la especie de zona de transǵresión que ocupan y en la que las prácticas habituales frente a los restos humanos pueden ser subvertidas en aras de la «búsqueda de la verdad» ${ }^{39}$. Crossland les considera como encargádos de la misión de «rearticular los muertos con los vivos $»^{40}$. Sin embargo, ellos también pueden desarticular dicha relación. En este caso, el hecho de que no se identificara a Eduardo González entre los tres cadáveres recuperados en el cementerio de Lecáun condujo a una verdad diferente: dos de los restos exhumados e identificados correspondían a los supuestamente ya exhumados clandestinamente en 1979 en el mismo cementerio por los habitantes de la cercana localidad de Cáseda. Allí construyeron un mausoleo para recibir los restos mortuorios de unos cuarenta represaliados del pueblo que recuperaron en total. Estos restos habían sido reaǵrupados en unas cajas de

\footnotetext{
${ }^{37}$ Moisseeff, 2016.

38 Delacroix y Losonezy, 2021.

39 Crossland, 2000. Para un análisis de la gestión de la frustración en los profesionales de las exhumaciones en Colombia, véase Aranguren Romero y Fernández Miranda, 2021.

${ }^{40}$ Crossland, 2000.
} 
madera marcadas con el nombre de la fosa común de la que fueron extraídos. La situación planteaba un problema evidente: si los restos exhumados en 2015 eran los que las familias pensaban haber recuperado a finales de los años setenta, ¿a quién sacaron en esa época? En marzo de 2016, con el acuerdo del Gobierno de Navarra, el equipo de Aranzadi se propuso verificar la identidad de los restos humanos procedentes del cementerio de Lecáun en 1979 para asegurarse de que el cuerpo de Eduardo no había sido llevado a Cáseda «por error».

Como en otros lugares de España, estos restos humanos fueron recuperados durante la transición democrática ante todo por su valor simbólico y colectivo ${ }^{41}$. La apertura, 36 años más tarde, del sepulcro erigido después de esta recuperación precoz de los restos fue en parte vivida por los habitantes de Cáseda como un cuestionamiento del esfuerzo colectivo realizado a finales del franquismo. Esta «comprobación de la verdad» («épreuve de vérité» en las palabras de Fassin ${ }^{42}$ ) fue sin embargo rápidamente abortada: el agua y la humedad habían degradado la madera, provocando de esta forma una mezcla de los huesos de más de cuarenta esqueletos. La operación de identificación fue por lo tanto abandonada. Las dos identificaciones de 2015 contradecían sin embargo aquellas, informales, realizadas en 1979. Sobre todo, confrontaban a las familias con resultados de laboratorio que estaban en contradicción con sus certezas.

La hija de una de las personas identificadas, de 90 años de edad, no dio ninguna importancia a estos resultados. Para ella, su «verdadero» padre era el que había sido desenterrado y «reconocido» por su familia en 1979, cuando ella tenía unos diez años. Como explica Alexa Hagerty ${ }^{43}$ a propósito de las exhumaciones en las que ella colaboró en Guatemala: «Las familias y los equipos forenses miden a veces los indicios según diferentes estándares, y fundan sus certezas en diferentes tipos de pruebas». De hecho, las familias «pueden ser convencidas más fácilmente por la ropa que por una identificación forense o incluso por el cotejo genético ${ }^{44}$. No obstante, la vestimenta, que es posible que haya podido ser intercambiada, no constituye una identificación científica a ojos de los expertos, sino solamente un indicio.

${ }^{41}$ Kerangat, 2019

42 En cuanto al derecho de asilo en Francia, Fassin (2010) analiza la «prueba por el cuerpo» a la que se somete a los solicitantes, es decir, la certificación por un médico de las huellas que la violencia puede haber dejado en su cuerpo. Explica que la insistencia en la «verdad del cuerpo» ha terminado por transformar la subjetividad política de los refugiados. En este caso, podemos observar un proceso similar. El análisis forense de los restos de la violencia franquista y carlista contribuye al reconocimiento público e institucional de las familias. El «sustrato último de la identidad» (Gatti y Mahlke, 2018) que el ADN ha lleǵado a constituir sirve así a un sistema ambiǵuo de leǵitimación de la condición de víctima.

${ }^{43}$ Hagerty, 2018.

${ }^{44}$ Hagerty, 2018. 
En España, el análisis de ADN surge a partir de comienzos del milenio como una nueva herramienta de identificación de las víctimas de la Guerra Civil. Antes, los objetos descubiertos junto con los restos humanos constituían los principales criterios de identificación. El sustrato genético sustituyó al objeto al tener un mayor grado de precisión, pero dicha exactitud también ha trastornado profundamente la igualdad del estatus entre los restos recuperados. Desde entonces algunos tienen un nombre mientras que otros $\mathrm{no}^{45}$. El peritaje forense también ha puesto en tela de juicio las interpretaciones anteriores, hechas a raíz de las exhumaciones tempranas y clandestinas de los decenios de 1970 y 1980. De hecho, muchos son los profesionales españoles de las exhumaciones que señalan el efecto perverso del ADN como herramienta sobrevalorada por las familias en busca del cuerpo de su pariente, en el sentido de que alimenta una nueva forma de competencia entre las víctimas.

En un contexto en el que la veracidad del nombre, establecida científicamente, tiene un impacto innegable, tanto las familias como los profesionales, a pesar de todo, tratan estos resultados de forma muy creativa y a veces con mucha libertad. Capaces de «adoptar» a un muerto que no es el suyo o de considerar adquirido que el cuerpo recuperado hace cuarenta años es efectivamente «su» difunto, las familias se ven a veces apoyadas por los profesionales que, en algunos casos, deciden silenciar la identidad real del muerto para evitar abrir de nuevo un ciclo de dudas y de sufrimiento.

Hay que destacar también el efecto generacional de la adopción simbólica de los restos exhumados. Es la nieta de un desaparecido la que «adopta» uno de los esqueletos encontrados en el pequeño cementerio de Lecáun. Estos huesos se convierten en un sustituto cómodo de los de su abuelo, quien sin embargó sigue en paradero desconocido. La hija de este hombre, por el contrario, no deseaba especialmente proceder a la exhumación. No impidió a sus hijas realizarla, pero para ella no era necesario hacerlo ya que le bastaba con los testimonios que indicaban el lugar de su enterramiento. Esta situación es interpretada por la generación de los nietos como el resultado de la interiorización de un miedo paralizador. Más de ocho décadas después de los hechos, las modalidades de duelo y de relación con la verdad difieren dentro de una misma familia, revelando vínculos con los muertos y con el pasado muy distintos. Estas demuestran que la sed de una respuesta «científicamente exacta» no está necesariamente unida a la proximidad temporal con los actos violentos.

\footnotetext{
${ }^{45}$ Un profesional de las exhumaciones español lo resume de esta manera: «El ADN ha tenido un efecto perverso en el sentido de que antes los restos recuperados eran todos iǵuales, mientras que ahora ya no lo son. Algunos tienen nombre, otros no» [Madrid, junio de 2019].
} 


\section{Conclusión}

En definitiva, buscar e identificar restos humanos, cuya materialidad está por lo general muy alejada de la imagen de la persona desaparecida, supone un trabajo de imaginación multiforme que ahonda en diferentes repertorios. Las interacciones entre las familias y los expertos generan una polifonía de interpretaciones y un reajuste de los rituales ordinarios. Así, los restos exhumados crean diferentes realidades. Son la prueba de un crimen (frecuentemente sin autores identificados), certifican o contradicen un relato, permiten acceder a un reconocimiento por parte de los actores políticos locales o iniciar un luto desde hace mucho tiempo aplazado. Más fundamentalmente, los materiales etnográficos invitan a considerar la gradación de la utilización, pública y privada, de los restos humanos, a partir de la elaboración de las posibilidades que estos abren, más allá de la lógica binaria de la despolitización/repolitización de las memorias de la guerra civil.

Vivir la experiencia de una exhumación puede transformar las convicciones personales y familiares. Alǵunos aceptarán la información basada en conocimientos forenses, otros se resistirán o la ignorarán, mientras que otros la encontrarán útil pero incompleta. La llegada de la ciencia como medio para esclarecer el drama de la guerra civil crea así un efecto variable y relativo que hace muy incierta la noción de fracaso. La etnografía ha revelado también nuevas formas de encarnación del difunto que llevan a prescindir del «verdadero» cuerpo del pariente asesinado, incluso a costa de «adoptar» otro. Las economías afectivas evolucionan entonces de manera singular con la recuperación o no de los restos humanos, luego con el homenaje que se les rinde y, cuando es posible, con el hecho de nombrarlos.

En otros casos, la aparición de restos humanos reactiva muchas cuestiones vinculadas a la posteridad de la violencia y a las zonas grises de la guerra civil. De hecho, algunos nietos de víctimas del franquismo luchan contra la focalización de la víctima fuera de toda sociología de los actores y por una imputación clara de las responsabilidades. Para ellos, la recuperación de los restos no loǵra expresar una verdad histórica completa. Los restos exhumados muestran la consumación de un crimen, pero los autores siguen ausentes. En resumidas cuentas, después de la larǵa ausencia de los cuerpos, las formas de resolución de las insatisfacciones de las familias presentan diversas configuraciones que portan de forma duradera la huella del pacto de silencio. Mientras la dialéctica de lo visible y de lo silenciado continúa fraǵmentando la relación íntima con los restos exhumados, un movimiento pendular entre una voluntad de denuncia de los perpetradores y de autorreparación de las heridas intergeneracionales conduce a los nietos a adoptar puntos de vista inéditos sobre este oscuro pasado y sobre la relación entre memoria, dignificación y emoción. 
Quizás, las cuestiones relacionadas con la herencia ideológica y con la filiación biológica están más presentes en España que en el Perú y en Guatemala por ejemplo, donde lo más importante es la necesidad de recuperar los restos, sorteando cualquier intromisión excesiva de las cuestiones políticas en estos. Por el contrario, se asiste en España a una politización del «régimen corpocéntrico de verdad, justicia y reparación asociado a la exposición pública de los huesos rescatados» en el que domina la referencia al parentesco con los desaparecidos ${ }^{46}$. Esta situación se puede relacionar probablemente con las décadas de omerta que han rodeado a las víctimas del franquismo. Desde la muerte del dictador, la sociedad española ha optado implícitamente por el olvido y el silencio al apoyar la política fundadora y consensual de la amnistía y de la reconciliación ${ }^{47}$. De esta forma «la imperiosa necesidad de poner fin a la profunda fractura provocada por la guerra civil, tantos años después de su fin oficial, prevaleció sobre la necesidad de pedir cuentas a los responsables de la dictadura. Así pues, los crímenes de la represión se mezclaron con los crímenes de guerra, ya que la necesidad de absolver a estos últimos para hacer posible la reconciliación nacional condujo a la disolución de las responsabilidades de los primeros ${ }^{48}$. En la actualidad no existe ninguna forma de reparación económica, ningún reconocimiento ni condena jurídica (por el momento), cuando ya han pasado ocho décadas desde el golpe de estado del general Franco. Los restos humanos ocupan en consecuencia un lugar central dentro de los regímenes de verdad que suceden al carácter descarnado de la muerte acaecida lejos de las familias, a menudo secretamente, y cuya realidad fue rodeada de un silencio social persistente.

Pero la nueva centralidad que adquieren, al ser expuestos a la luz pública, es ambivalente. Cuerpo prueba, cuerpo recurso político, cuerpo artefacto, cuerpo adoptado bajo una identidad ficticia, cuerpo medio y límite de imputación de responsabilidades: mi etnografía ilustra los diferentes sentidos atribuidos a los restos exhumados. En realidad, las experiencias concretas de «verdad» se ponen a prueba de forma muy variada entre y dentro de los contextos. Estas experiencias se apoyan, en efecto, en las diferentes huellas que articulan registros contradictorios y complementarios. Los saberes son forenses, archivísticos, locales. Las movilizaciones pueden ser colectivas o privilegiar el luto individual, y los registros afectivos y políticos se entremezclan. Mi análisis demuestra que diferentes formas de apaciǵamiento están en tensión entre dos polaridades: por una parte, la discursividad y por otra la materialidad de los restos.

\footnotetext{
${ }^{46}$ Ferrándiz, 2018, p. 301.

47 Baby, 2007; Julia, 2000.

48 Baby, 2007.
} 


\section{Bibliografía}

Aguilar Fernández, Paloma, «El primer ciclo de exhumaciones y homenajes a fusilados republicanos en Navarra», Kamchatka. Revista de análisis cultural, 13, 2019, pp. 227-269.

Altafaylla, Navarra 1936. De la esperanza al terror, Tafalla, Txalaparta, 2018.

Anstett, Élisabeth, y Jean-Mare Dreyfus (dirs.), Human Remains and Identification. Mass Genocide, Violence and the «Forensic Turn», Manchester, Manchester University Press, 2015.

Aranguren Romero, Juan Pablo, y Gabriela Fernández Miranda, «Gestionar la frustración: experiencias relacionales de antropólogas forenses en el contexto del conflicto armado colombiano», Nuevo Mundo Mundos Nuevos. doi: https://doi. orǵ/10.4000/nuevomundo.83956

Baby, Sophie, «Sortir de la guerre civile à retardement: le cas espagnol»,Histoire @ Politique, 3, 2007, https://www.cairn.info/revue-histoire-politique-2007-3-page-12. htm [consultado el 28/05/2021]

Capdepón, Ulrike, «Memorias familiares, identidades reprimidas y vida política de los cadáveres: el significado actual de las narrativas de parentesco en las exhumaciones de la guerra civil española», en Gabriel Gatti y Kirsten Mahlke (dirs.), Sangre y filiación en los relatos del dolor, Madrid-Frankfurt, IberoamericanaVervuert, 2018, pp. 235-253.

Crossland, Zoé, «Buried lives: forensic archaeology and Argentina's disappeared», Archaeological Dialogues, 7.2, 2000, pp. 146-159.

Das, Veena, Violencia, cuerpo y lenguaje, México, Fondo de Cultura Económica, 2016.

Delacroix, Dorothée, «Ouvrir les fosses communes au Pérou: «Envoyer au ciel» les objets trouvés ou les commercialiser?», Les Cahiers Sirice, 2.2, 2017, pp. 105-122. doi: https://doi.org/10.3917/lesi.019.0105

Delacroix, Dorothée, «Le bal des âmes. Postérité de la mort de masse en contexte péruvien», Terrain, 2018. doi: https:// doi.org/10.4000/terrain.16819

Delacroix, Dorothée, y Camille Noûs, «Politiques du doute et régímes de vérité à «l'ère de l'os». ADN et adoptions symboliques des corps récupérés dans les charniers au Pérou et en Espagne», Ethnologie française, 178.2, 2020, pp. 327-344. doi: https://doi.org/10.3917/ethn.202.0327

Delacroix, Dorothée, y Anne-Marie Losonczy, «Exhumaciones inacabadas. Equivocaciones y contingencias de la búsqueda de cuerpos en contextos posconflicto latinoamericanos y europeos», Nuevo Mundo Mundos Nuevos, 2021. doi: https://doi. org $/ 10.4000 /$ nuevomundo. 84348

Douglas, Lee, «Buscar, pero no encontrar: la producción del conocimiento histórico en un mundo de ausencias», Nuevo Mundo Mundos Nuevos, 2021. doi: https://doi. org/10.4000/nuevomundo.84053

Dziuban, Zuzanna (ed.), Mapping the «Forensic Turn»: engagements with materialities of mass death in holocaust studies and beyond, Vienne, New Academic Press, 2017. 
Etxeberria, Francisco, y Queralt Solé, «Fosas comunes de la Guerra Civil en el siǵlo XXI: antecedentes, interdisciplinariedad y legislación», Historia Contemporánea, 60, 2019, pp. 401-438. doi: https://doi.org/10.1387/he.20310

Fassin, Didier, La raison humanitaire. Une histoire morale du temps présent, Paris, Editions de l'EHESS-Seuil, 2010.

Fernández de Mata, Iǵnacio, Lloros vueltos puños. El conflicto de los «desaparecidos» y vencidos de la guerra civil española, Granada, Comares Historia, 2016.

Ferrándiz, Francisco, El pasado bajo tierra. Exhumaciones contemporáneas de la Guerra Civil, Barcelona, Anthropos, 2014.

Ferrándiz, Francisco, «De la lágrima al píxel: corrección política y emociones digitales en las exhumaciones de fosas comunes de la Guerra Civil», en Luisa Elena Delgado, Pura Fernández, y Jo Labanyi (coords.), La cultura de las emociones y las emociones en la cultura española contemporánea: (siglos XVIII-XXI), 2018, pp. 293-318.

Ferrándiz, Francisco, y Antonius Robben (eds.), Necropolitics. Mass Graves and Exhumations in the Age of Human Rights, Philadelphia, University of Pennsylvania Press, 2015.

Foucault, Michel, Du gouvernement des vivants. Cours au Collège de France. 19781979, Paris, Seuil/Gallimard, 2012 [1979].

Garmendia Amutxastegi Gotzon, y Juan Carlos García Funes, «La «Ley de Memoria Histórica de Navarra». Movimiento(s) por la recuperación de la Memoria Histórica y políticas públicas», Boletín de la Sección de Historia de la FIM, 3, 2015, pp. $70-77$.

Gatti, Gabriel, «Cuando la sangre (de las víctimas) gobierna la memoria», Rubrica, 2014a, https://f.hypotheses.org/wp-content/blogs.dir/2333/files/2015/02/Cuando-lasangre-de-las-víctimas-gobierna-la-memoria1.pdf [consultado el 28/05/2021].

Gatti Gabriel, Surviving Forced Disappearance in Argentina and Uruguay. Identity and Meaning, New York, Palgrave Macmillan, 2014b.

Gatti, Gabriel, y Elisabeth Anstett (dirs.), «Sangres políticas», Athenea Digital, 18.1, 2018, pp. 3-9. doi: https://doi.org/10.5565/rev/athenea.2378

Gatti, Gabriel, y Kirsten Mahlke (dirs.), Sangre y filiación en los relatos del dolor, Madrid-Frankfurt, Iberoamericana-Vervuert, 2018.

Hagerty, Alexa, «Drowning the dead», Carnet de Terrain. Le blog de la revue Terrain, 2018, https://blogterrain.hypo-theses.org/11852 [consultado el 28/05/2021].

Hartog, François, Régimes d'historicité. Présentisme et expérience du temps, Paris, Le Seuil, 2003.

Juliá, Santos, y José Carlos Mainer, El aprendizaje de la libertad. 1973-1986: la cultura de la transición, Madrid, Alianza, 2000.

Kerangat, Zoé de, «Beyond Local Memories: Exhumations of Francoism's Victims as Counter-discourse during the Spanish Transition to Democracy», en Andersen Tea Sindbæk, y Barbara Törnquist-Plewa (dirs.), The Twentieth Century in European Memory, Leiden/Boston, Brill, 2017, pp. 104-121.

Kerangat, Zoé de, «Remover cielo y tierra: las exhumaciones de víctimas del franquismo como fisuras del silencio en la transición», tesis doctoral, Universidad Autónoma de Madrid, 2019. 
Memmi, Dominique, La Revanche de la chair. Essai sur les nouveaux supports de l'identité, Paris, Seuil, 2014.

Mikelarena, Fernando, Sin piedad. Liempieza politica en Navarra, 1936. Responsables, colaboradores, ejecutores, Pamplona, Pamiela, 2015.

Moisseeff, Marika, «Cadavre et churinga. Des objets cultuels exemplaires?», Archives de sciences sociales des religions, 174, 2016, pp. 255-278.

Montoto Ugarte, Marina, «The 'querella argentina' as a Transnational Site of Memory of the Victims of Francoism», en Miguez Macho, An, Sites of Violence and Memory in Modern Spain: From the Spanish Civil War to the Present Day, Londres, Bloomsburry, 2021 (en prensa).

Panizo, Laura Marina, "Ausencia y desaparición: el caso de los desaparecidos de la última dictadura militar en Argentina», Argos, 2, 2012, pp. 94-125.

Robin Azebedo, Valérie, «¿Devolver la dignidad a los desaparecidos del conflicto armado peruano? Exhumaciones, justicia transicional y políticas de la compasión», en Losonczy, Anne-Marie, y Robin Azevedo, Valérie, Retorno de los cuerpos, recorrido de las almas. Exhumaciones y duelos colectivos en América Latina y España, Universidad de los Andes/IFEA, Lima, 2021, pp. 27-53. doi: http:// dx.doi.org/10.30778/2020.11

Robledo Silvestre, Carolina, Drama social y política del duelo. Las desapariciones de la guerra contra las drogas en Tijuana. Ciudad de México, El Colegio de México, 2017.

Sorrentino, Paul, A l'épreuve de la possession: chronique d'une innovation rituelle dans le Vietnam contemporain, Nanterre, Société d'Ethnologie, 2018.

Sosa, Cecilia, Queering Acts of Mourning in the Aftermath of Argentina's Dictatorship. The Performances of Blood, New-York, Tamesis Books, 2014.

Verdery, Katherine, The Political Lives of Dead Bodies, New York, Columbia University, 1999.

Winter, Jay, Sites of Memory, Sites of Mourning: The Great War in European Cultural History, Cambridge, Cambridge University Press, 1995. 
